\title{
LAS FUENTES GRÁFICAS DE LAS PINTURAS BARROCAS DE LOS PADRES DE LA IGLESIA DE MENDIGUREN (ÁLAVA) Y LA CERCA (BURGOS). FORTUNA DE UNA INVENCIÓN DE PIETER DE WITTE
}

José Javier Vélez Chaurri Pedro Luis Echeverría Goñi Universidad del País Vasco

RESUMEN: Analizamos aquí las pinturas barrocas de los Padres de la Iglesia de las parroquias de Mendiguren (Álava) y La Cerca (Burgos). Forman parte de sendos programas contrarreformistas del siglo XVII en los que se exalta a la Asunción y la Inmaculada respectivamente. Estas obras son copias de los grabados de A. Sadeler II y J. F. Greuter a partir de una creación de Pieter de Witte.

Palabras clave: Pintura barroca, siglo XVII, Mendiguren, La Cerca, Padres de la Iglesia, grabado, Pieter de Witte, Aegidius Sadeler II, Johann Friedrich Greuter.

\section{GRAPHIC SOURCES FOR THE BAROQUE PAINTINGS OF THE CHURCH FATHERS FROM MENDIGUREN (ÁLAVA) AND LA CERCA (BURGOS). THE FORTUNE OF AN INVENTION BY PIETER DE WITTE}

ABSTRACT: We analyze here the baroque paintings of the Fathers of the Church in the parishes of Mendiguren (Álava) and La Cerca (Burgos). They are part of two counter-reformer's programs in the seventeenth century which exalt the Assumption and the Immaculate respectively. These works are copies of engravings by A. Sadeler II and J. F Greuter, after Pieter de Witte.

Keywords: Baroque painting, Seventeenth century, Mendiguren, La Cerca, Church-Fathers, engraving, Peter de Witte, Aegidius Sadeler II, Johann Friedrich Greuter.

Analizamos en este trabajo dos programas iconográficos contrarreformistas del siglo XVII que presentan a la Virgen exaltada por los cuatro Padres de la Iglesia Latina. El actual retablo alavés de Mendiguren reaprovecha los lienzos de San Agustín, San Ambrosio, San Jerónimo y San Gregorio Magno que escolta- 
ron a un cuadro de la Asunción desaparecido. En la localidad burgalesa de La Cerca se ha conservado un retablo de la Inmaculada Concepción flanqueada por las tablas de los Doctores. En ambos casos se inspiran en dos series de grabados a partir una creación de Pieter de Witte que tuvo gran fortuna en el siglo XVII y todavía inspiró cuadros de los Padres en los siglos XVIII y XIX. Estudiamos aquí el contexto histórico en el que se llevaron a cabo, los clientes que los encargaron y el grado de dependencia con las estampas que los inspiraron. En torno a 1630 se ensambló el retablo de la Inmaculada de la capilla de los Hierro-Salinas de La Cerca y, superado el ecuador del siglo, se pintaron los lienzos de los Padres de la Iglesia del primer retablo mayor de la parroquia de la Asunción de Mendiguren. La serie creada por P. de Witte fue trasladada tempranamente al buril por grabadores como Aegidius Sadeler II que reprodujo fielmente los tipos y las iconografías del artista flamenco e inspiró pinturas como las de Mendiguren. Otras series como la de Greuter copiaron los tipos y actitudes pero alteraron sus iconografías intercambiando tocados y atributos. Consecuencia de estas transformaciones es la confusión iconográfica y las duplicaciones que se advierten en las pinturas de La Cerca.

\section{María y los Padres de la Iglesia}

Ante el rechazo de los protestantes de la virginidad y del papel intercesor de María, se intensificó en todas las capas de la sociedad española la devoción mariana y la creencia firme en la Inmaculada Concepción y la Asunción de la Virgen a los cielos siglos antes de sus declaraciones como dogmas de fe en 1854 y 1950 respectivamente. Los reyes españoles, recogiendo este sentir popular, solicitaron a los papas a lo largo del siglo XVII la proclamación como dogma de fe de la concepción sin mancha de la Virgen. Los hitos principales de este proceso fueron las bulas de los papas Pablo V (1617), Gregorio XV (1622) y, principalmente, Alejandro VII (1661) con la "Sollicitudo Omnium Ecclesiarum"1. La defensa que los Padres de la Iglesia Latina habían hecho en sus escritos de la virginidad de María y de su condición de Madre de Dios volvía a ser necesaria tras la Reforma protestante. Algunas de sus representaciones pictóricas y escultóricas barrocas aparecen desde comienzos del siglo XVII acompañadas por los cuatro Padres y otros doctores como autoridades morales en las que respaldar la devoción a María. Algunos de los jalones iconográficos fundamentales proceden de Sevilla y son los lienzos de la Alegoría de la Inmaculada Concepción (1616) de Juan de Roelas y la Alegoría de la Eucaristía y la Inmaculada Concepción (1665) de Juan de Valdés Leal'2. Son menos los lienzos barrocos en los

1. STRATTON, S., "La Inmaculada Concepción en el arte español", Cuadernos de Arte e IConografía, 2 (1988), pp. 3-128.

2. Ibídem, pp. 62 (Roelas) y 88-89 (Valdés Leal). 
que se representa de forma exclusiva a la Tota Pulchra acompañada de los cuatro Padres, como los realizados por el Domenichino, donde se agrupan a los pies de la Virgen³, o el que realizó el pintor novohispano Tomás Fernández de Heredia en 1673, disponiéndose en los ángulos.

Los santos Padres, que hasta 1600 se situaban en los bancos de los retablos hispanos como fundamento y legitimación de la doctrina cristiana, cobrarán a partir de ese momento un mayor protagonismo como lo demuestran los conjuntos estudiados en este trabajo. Los cuadros de La Cerca flanquean en las calles laterales a una talla de la Inmaculada Concepción y en el primitivo retablo de Mendiguren lo hacían escoltando a un cuadro de la Asunción. La representación de advocaciones marianas acompañadas por los Padres de la Iglesia Latina es mucho menos abundante en el siglo XVII que sus iconografías individuales. En cualquier caso responde a la búsqueda en sus escritos de criterios de autoridad moral e intelectual para la defensa del papel de María en la redención del género humano. Es ahora cuando se vuelven a actualizar escritos apologéticos marianos para refutar las herejías del siglo IV como los redactados por San Jerónimo, San Agustín, San Gregorio Magno y San Ambrosio ${ }^{4}$. En uno de los ejemplos con estas iconografías combinadas, el retablo mayor de la iglesia parroquial de La Riba de Santiuste (Guadalajara) realizado en 1689, se ordena en una de las cláusulas del contrato "acomodar los quatro lienzos de pintura (de los Doctores de la Iglesia) que da el Señor Don Gerónimo del Olmo en los yntercolunos con sus marcos guarnezidos de talla según están en la traza" ${ }^{5}$. En la misma escritura se dispone la ejecución de una talla de la Asunción para la calle central. La presencia de los Padres escoltando a María se justifica aquí, como en Mendiguren, por el interés particular de destacados miembros de la jerarquía eclesiástica, imbuidos de fervor mariano.

\section{La fortuna de la serie "inventada" por Pieter de Witte}

Acorde con los "estados" o clases de pintores que establece Pacheco y otros tratadistas del barroco hispano, no podemos considerar a los anónimos autores de los cuadros de Mendiguren y La Cerca como pintores "aprovechados" y a sus obras como dotadas de invención, ya que son copias literales de las estampas de las series de Sadeler y Greuter. Para el tratadista sevillano el segundo gra-

3. MÂLE, E., El arte religioso de la Contrarreforma, Madrid, Encuentro, 2001, p. 55.

4. MARTINO ALBA, P., "Iconografía de los Padres de la Iglesia en torno a la Inmaculada Concepción", en Campos, F. J. (coord.), La Inmaculada Concepción en España: religiosidad, historia y arte. Actas del Simposio, vol. II, San Lorenzo de El Escorial, Instituto Escurialense de Investigaciones Históricas y Artísticas, 2005, pp. 719 y 721-723.

5. MARCO MARTÍNEZ, J. A., El retablo barroco en el antiguo obispado de Sigüenza, Guadalajara, Diputación Provincial de Guadalajara, 1997, pp. 212-215. Jerónimo del Olmo y Manrique fue chantre y canónigo de la catedral de Sigüenza. 
do de los pintores es el de los que "aprovechan y teniendo munchas cosas juntas, de valientes hombres, así de estampa como de mano, ofreciéndosele ocasión de hacer alguna historia, se alarga a componer, de varias cosas de diferentes artífices, un buen todo" ${ }^{\prime \prime}$. En este sentido la invención de esta serie de los cuatro Padres de la Iglesia corresponde al pintor y grabador manierista Pieter de Witte (c. 1548-1628) ${ }^{7}$. Este maestro, nacido en Brujas, desarrolló gran parte de su actividad profesional en Italia en el taller de Vasari, para quién trabajó en las pinturas al fresco de la Sala Regia del Vaticano y en la cúpula de la catedral de Florencia, siendo conocido en el país trasalpino como Pietro Candido. La década de los ochenta coincide con la elaboración de un buen número de dibujos que serían grabados sucesivamente en siglos posteriores. Ya Van Mander afirma que las estampas realizadas a partir de invenciones suyas constituyen una buena prueba de su talento. Desde 1586 fue artista de cámara en la corte del príncipe elector de Baviera en Munich donde murió. Una obra capital de su madurez fue el cuadro de la Asunción de la Virgen de la catedral de Nuestra Señora de Munich (1620), tema contrarreformista de estilo ya protobarroco. Así pues, la filiación estilística de esta serie de los Padres de la Iglesia, dibujada por este pintor, se entronca en el manierismo florentino y en una mirada retrospectiva a Miguel Ángel. La característica actitud de San Agustín nos remite a creaciones miguelangelescas de tipos contemplativos como el Lorenzo de Medici de las tumbas de la sacristía de San Lorenzo de Florencia o al réprobo desesperado por la condenación eterna del Juicio Final de la Sixtina.

Entre los grabadores que difundieron esta serie de los Doctores destacan el flamenco Aegidius Sadeler II (1570-1629) ${ }^{8}$ y el alemán Johann Friedrich Greuter (c. 1590-1662). El primero fue el miembro más destacado de la dinastía de los Sadeler ${ }^{9}$, grabadores de Amberes, que difundió su arte en Colonia, Munich, Roma, Verona, Venecia y Praga. A partir de la última década del siglo XVI sus grabados manieristas se inspiran en pinturas de artistas flamencos, principalmente Martin de Vos, y, en última instancia, de Tiziano, Rafael, Miguel Ángel, Parmigianino, Tintoretto y Barocci. Su serie de estampas de los cuatro Padres de

6. PACHECO, F., Arte de la Pintura, Edición, introducción y notas de B. Bassegoda i Hugàs, Madrid, Cátedra, p. 269.

7. VAN MANDER, K., Le libre des peintres, París, Les Belles Lettres, 2002, pp. 187-188. MORETTI, M., Lettere di Pieter de Witte. Pietro Candido nei carteggi di Antonio Maria Graziani (1569-1574), Roma, De Luca Editori d'Arte, 2013. BURRESSI, M. J. y CECCHI, A., Pieter de Witte-Pietro Candido. Un pittore del Cinquecento tra Volterra e Monaco, Catalogo della mostra, Milano, Silvana Editoriale, 2009.

8. The IIlustrated Bartsch, 72, part I (Supplement), Aegidius Sadeler II, New York, Abaris Books, 1997, pp. 1-2 (datos biográficos) y 161-167 (serie de los cuatro Padres de la Iglesia).

9. GONZÁLEZ DE ZARATE, J. M., LAMARCA RUIZ DE EGUILAZ, R., y BERMEJO VEGA, V., "Las estampas de los Sadeler como transmisoras de modelos iconográficos en la pintura flamenca del siglo XVII", Goya, 251 (1996), pp. 265-275. 
la Iglesia, creada a partir de P. de Witte, fue editada por Marco Sadeler. Greuter fue un grabador natural de Estrasburgo que trabajó en Roma para la familia de los Barberini, para quienes ilustró un buen número de libros. Su época más fecunda fue el segundo tercio del siglo XVII a partir de la apertura de su taller en 1638. Lo podemos considerar un artista barroco pues reprodujo obras de Bernini, Pietro di Cortona o Vouet. En el British Museum se conservan tres de los Padres de su serie que fue editada por Hendrik Van Schoel ${ }^{10}$.

Del éxito de las series grabadas de los cuatro Padres dibujadas por Pieter de Witte son una buena prueba, además de los cuadros que estudiamos aquí, las tablas de San Gregorio Magno y San Agustín del banco del retablo de San Benito de la catedral de Pamplona, pintadas antes de 1651 por el pintor de origen burgalés Lucas de Pinedo"11. Las que representaban a los otros dos Doctores desaparecieron en una reforma que sufrió este retablo en el siglo XVIII. Algo posteriores son los dos cuadros de San Ambrosio y San Agustín, restos de otra serie, que se custodian junto a diversas pinturas barrocas en la sacristía de la parroquia de San Pedro de Vergara ${ }^{12}$. La pintura que representa a San Agustín es la única en la que se copia también al niño de la leyenda sobre la demostración de la Trinidad. Estos modelos estuvieron todavía vigentes en los siglos XVIII y XIX como lo atestigua la serie pintada en 1866 por el pintor vitoriano Epifanio Díaz de Arcaute para la sacristía nueva de la catedral de Santa María de Vitoria. Tres de los lienzos siguen con fidelidad los grabados respectivos de Aegidius Sadeler II y no así el que representa a San Ambrosio ${ }^{13}$. La estampa de Sadeler del obispo de Milán ha servido de modelo aquí para San Isidoro de Sevilla.

\section{Los lienzos barrocos de Mendiguren}

Preside la capilla mayor gótico-renacentista de la parroquia de Mendiguren ${ }^{14}$ un sencillo retablo neoclásico que aloja entre dos pilastras de orden gigante una

10. Department of Prints and Drawings. British Museum. San Jerónimo (n⿳⼈ 1872, 1012.3460), San Agustín (no 1872, 1012.3463) y San Gregorio (no 1872, 1012.3462).

11. GARCíA GAINZA, M. C. y otros, Catálogo Monumental de Navarra, T. V***, Pamplona, Gobierno de Navarra, 1997, p. 68.

12. ARAMBURU EXPOSITO, M.․‥, Arte y Piedad. El arte religioso en Bergara en la Edad Moderna, T. I, Salamanca, Ayuntamiento de Bergara, 2008, pp. 278-279. La autora señala que estas pinturas están inspiradas en grabados, probablemente de Goltzius y las relaciona con los cuadros de la catedral de Pamplona y Mendiguren. Además recoge que en el inventario del capitán Ignacio de Iturbe de 1688 se cita una serie de los cuatro Doctores de la Iglesia.

13. BARTOLOMÉ GARCÍA, F. R., "Conjunto pictórico en la sacristía de la catedral de Santa María de Vitoria-Gasteiz", Ars Bilduma, 1 (2011), pp. 73-78.

14. La localidad de Mendiguren estuvo integrada en la Hermandad de Badayoz, una de las seis alavesas del señorío del duque del Infantado, junto a otros once pueblos de su entorno: Artaza, Guereña, Mandojana, Legarda, Antezana de Álava, Foronda, Aranguiz, Yurre, Lopidana, Asteguieta y Ullivarri-Viña. En su término se localizaba la ermita de Nuestra Señora de la 


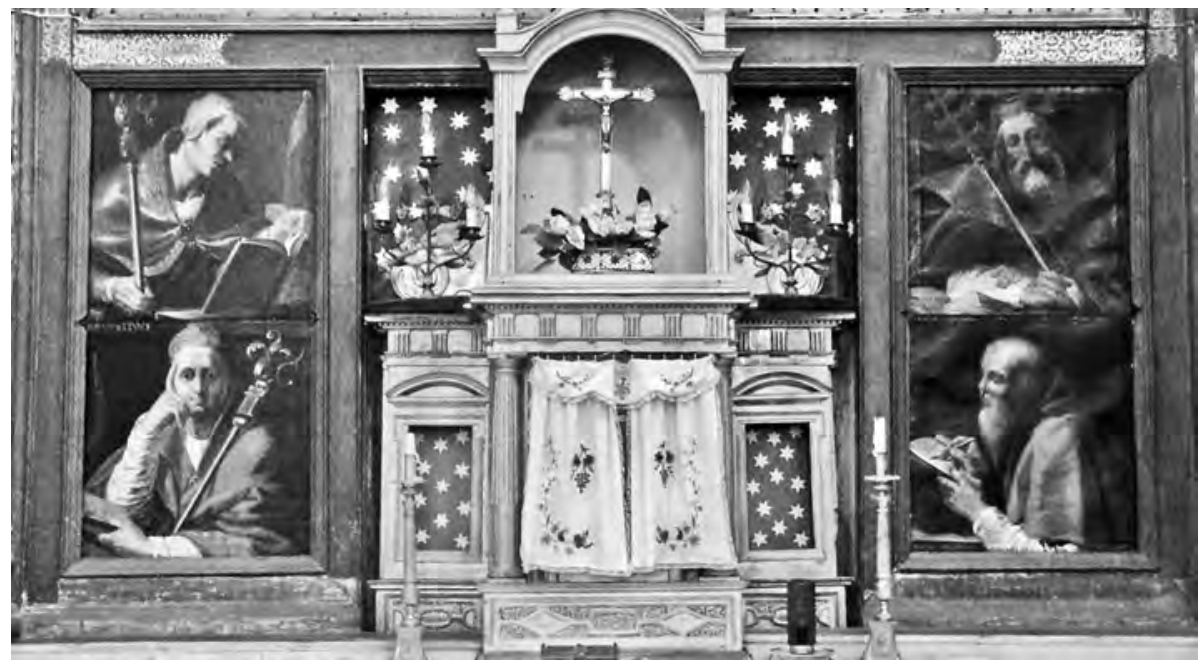

Figura 1. Banco con sagrario romanista y lienzos de los Padres de la Iglesia. Retablo mayor. Parroquia de la Asunción. Mendiguren (Álava).

copia de mediados del siglo XIX de la Inmaculada Concepción pintada por Juan Carreño de Miranda para el monasterio de San Francisco de Vitoria ${ }^{15}$. En su actual disposición se reaprovechan en el banco el sagrario romanista y cuatro lienzos barrocos de los Padres de la Iglesia, superpuestos dos a dos (Fig. 1). Con antelación a este retablo la iglesia debió contar con una talla de la Asunción, titular del templo, y el sagrario de fines del siglo XVI que todavía se conserva. Es sin duda uno más de los tabernáculos salidos del taller vitoriano de Esteban de Velasco para pueblos de la Llanada alavesa ${ }^{16}$, que fue dorado en $1737^{17}$. Se presenta en forma de templete con alas, columnas toscanas, entablamento dórico, frontones curvos y decoración de encadenados geométricos en el primer cuerpo. Desaparecido el expositor original solo se han conservado los aletones con los típicos

Antigua en la cual celebraban sus juntas la popular cofradía de los arrieros de San Antón de Legarda y Nuestra Señora Santa María la Antigua de Mendiguren. Sus ordenanzas fueron capituladas en 1532 y aprobadas por Carlos I en 1537 en Valladolid.

15. Fue tal el prestigio de esta obra, entonces ya custodiada en la catedral de Vitoria, que destacados pintores alaveses como José López de Torre y, más tarde, Epifanio Díaz de Arcaute, hicieron diversas réplicas de este lienzo.

16. ECHEVERRÍA GOÑI, P. L. y VÉLEZ CHAURRI, J. J., "La aportación de Esteban de Velasco al Romanismo alavés", en ZALAMA, M. A. y MOGOLLÓN, P. (coords.), Alma Ars. Estudios de Arte e Historia en Homenaje al Dr. Salvador Andrés Ordax, Valladolid, Universidad de Valladolid y Universidad de Extremadura, 2013, pp. 111-120.

17. PORTILLA VITORIA, M. J., Catálogo Monumental. Diócesis de Vitoria. Tomo IV, La Llanada alavesa occidental, Vitoria, Caja de Ahorros Municipal de Vitoria, 1975, p. 528. 
niños recostados. En su portezuela encontramos un relieve de Cristo resucitado sedente que porta en su mano izquierda una monumental cruz y la bola como Salvador del mundo, idéntico al de la puerta del sagrario de Berrosteguieta ${ }^{18}$.

Sabemos que posteriormente Ilegaron a la parroquia cinco lienzos barrocos, una Asunción y los cuatro Padres de la Iglesia, que todavía se conservan. Para albergarlos se compuso un retablo mayor clasicista presidido por la Asunción, flanqueada seguramente en las calles laterales por San Agustín y San Ambrosio en la del evangelio y San Jerónimo y San Gregorio Magno en la de la epístola. Son obras realizadas superado ya el ecuador del siglo XVII y con antelación a 1674, cuando se registran pagos por "componer y limpiar el Retablo del altar mayor"19. Al comparar las tablas de Mendiguren con los grabados que las inspiran comprobamos que aquéllas fueron recortadas en 1801 para adaptarlas a su nueva ubicación en el marco del retablo neoclásico. Tras esta intervención se han reducido a la mínima expresión elementos como mitras y tiara y se ha eliminado algún otro como la cruz de San Jerónimo. En el actual retablo neoclásico, fabricado por José de Aguirre ${ }^{20}$, se integraron el sagrario y los cinco cuadros. A mediados del siglo XIX fue robado el lienzo de la Asunción, que debía ser obra de gran calidad, como lo atestigua la elocuente frase que en 1890 le dedica el cronista alavés Becerro de Bengoa: "Tuvo la Iglesia un gran cuadro de la Assumpción, obra de Ticiano, que fue robado hace cincuenta años" ${ }^{21}$. En 1857, tras su robo, se colocó en su lugar la citada copia de la Inmaculada de Carreño, pero se ha conservado en la sacristía el marco barroco original.

Aunque desconocemos la vía de llegada de estos cuadros a Mendiguren, existe una tradición oral que los vincula a Juan Bautista de Arzamendi (16351720), colegial de la Santa Cruz de Valladolid, inquisidor de Granada y obispo electo de Zamora y Pamplona, natural de la cercana localidad de Mendarózqueta. Sabemos que fundó una capellanía en su pueblo natal ${ }^{22}$ y dotó a la capi-

18. En el ático del colateral de Santa Catalina de Sotés (La Rioja) encontramos un relieve con una versión más monumental de esta iconografía salida de la gubia de Juan Fernández de Vallejo. Creemos que el modelo común parte de Juan de Anchieta y se basa en el Cristo del Juicio Final de Miguel Ángel en la capilla Sixtina.

19. Archivo Diocesano de Vitoria. 1747-1. Mendiguren, 3, Libro de Fábrica, 1650-1703, fol. $65 \mathrm{v}$.

20. PORTILLA VITORIA, M. J., ob. cit., pp. 527-528.

21. BECERRO DE BENGOA, R., "Lugares curiosos de Álaba". Euskal-Erria, 1890, p. 338. Esta elogiosa atribución del erudito vitoriano del lienzo del Mendiguren solo puede justificarse por la inspiración del cuadro en grabados manieristas, entre ellos de Sadeler, a partir del genial pintor veneciano.

22. MATEO PÉREZ, A., "La 'fundación de patronatos': Fuente para el estudio de una realidad espiritual, social y artística", en PORRES, R. (dir.), Aproximación metodológica a los Protocolos Notariales de Álava (Edad Moderna), Bilbao, Universidad del País Vasco, 1996, pp. 367-370 y 373. 

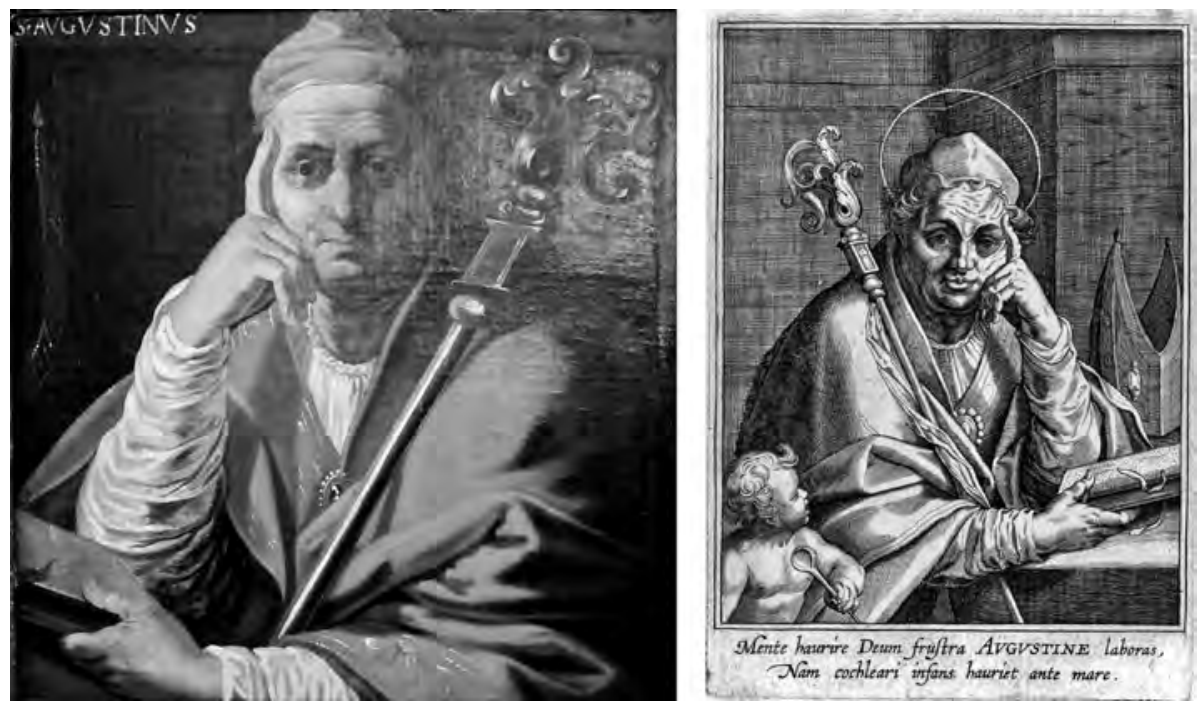

Figura 2. San Agustín. Mendiguren; Aegidius Sadeler II. Grabado de San Agustín.

Ila con varios cuadros entre los que destaca su retrato con la Inmaculada de la que fue un ferviente defensor ${ }^{23}$.

En el banco del retablo del siglo XIX se disponen, a ambos lados del sagrario y enmarcados dos a dos, los lienzos de San Agustín y San Ambrosio y los de San Jerónimo y San Gregorio Magno. Se trata de pinturas de buena factura que se inspiran en la serie de Aegidius Sadeler II a partir de Pieter de Witte. La tabla de San Agustín (Fig. 2) representa al obispo de Hipona como doctor de la iglesia en actitud contemplativa, apoyando su rostro sobre la mano derecha, y mirando fijamente al fiel. Identificado por la inscripción "S. AVGVSTINVS", pintada en la parte superior del lado izquierdo del espectador, representa a un hombre de mediana edad y lampiño que viste alba, capa pluvial roja, cerrada con un broche con perlas, y el gorro redondo que recuerda al camauro. Apoya sobre su cuerpo el báculo con nudo prismático y artística voluta de tallos vegetales en tanto que con su mano izquierda sujeta el libro. A su derecha asoma parte de la mitra episcopal apoyada sobre el escritorio. Respecto al grabado de Sadeler, en el cuadro de Mendiguren se ha eliminado al niño de la leyenda de San Agustín meditando sobre la Trinidad. Otro detalle que no se ha trasladado al cuadro es la filacteria que aparece enrollada al báculo.

23. PORTILLA VITORIA, M. J., ob. cit., pp. 522-523. 

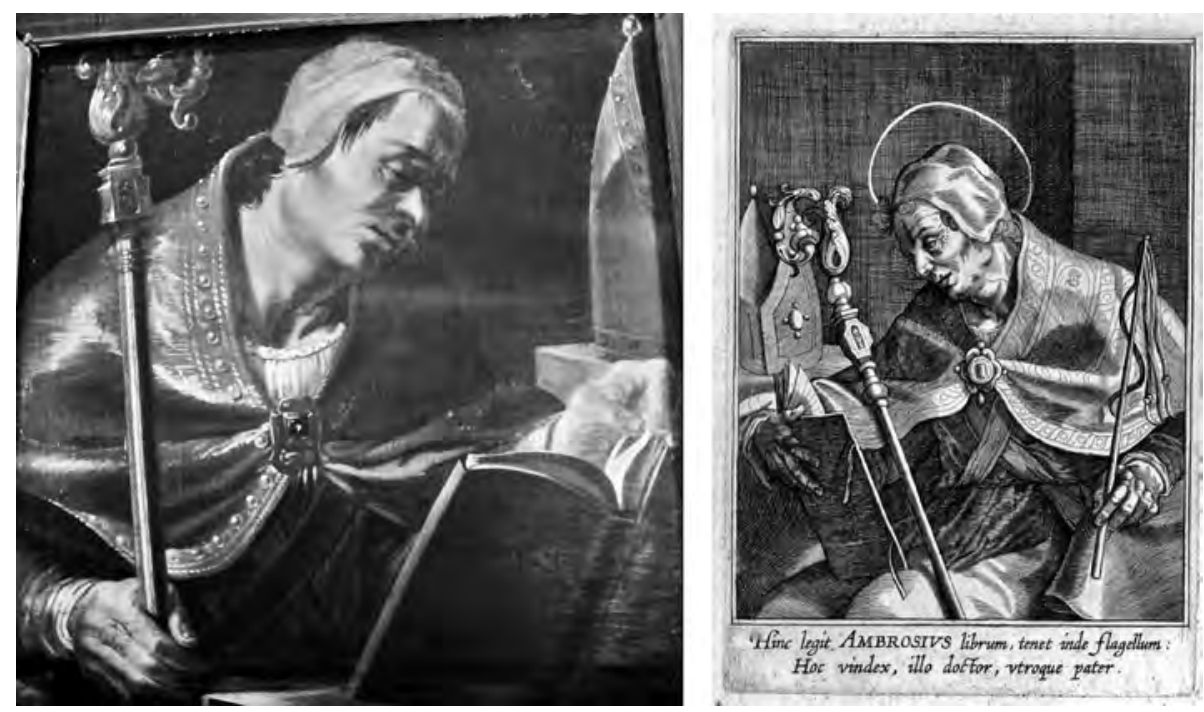

Figura 3. San Ambrosio. Mendiguren; Aegidius Sadeler II. Grabado de San Ambrosio.

San Ambrosio (Fig. 3) es representado en este retablo como un hombre maduro, sin barba y en actitud de leer, concentrado y en silencio, como decía San Agustín. Viste alba, estola cruzada sobre el pecho y capa pluvial dorada cerrada por broche. Cubre su cabeza y orejas un gorro similar al de San Agustín. La mitra aparece depositada sobre una mesa y lleva como atributos el citado libro y el báculo. Las principales diferencias que advertimos son la eliminación del látigo con tres nudos, el cambio de disposición del báculo y la disposición de la mano que sujeta el libro.

Aparece San Jerónimo (Fig. 4) como un anciano calvo y de poblada barba canosa y con la actitud de erudito que corresponde al Doctor de la Iglesia. Identificado por la inscripción "S. JERONIMVS", el santo se halla escribiendo la Vulgata. La leyenda "In principio creavit Deus caelum et terram...", que figura al pie de la estampa de A. Sadeler, alude a la traducción de la Biblia al latín. El vivo color rojo de su esclavina con capucha y del capelo con borlas colgado de la pared lo identifica como cardenal. Le caracteriza como penitente la calavera dispuesta sobre la mesa que sirve de atril al libro. Respecto al grabado flamenco el pintor de Mendiguren ha suprimido el león de la leyenda y dos elementos de la vanitas, el crucifijo y el reloj de arena. También ha quitado el nimbo que le corona y el mechón de cabello de su frente.

San Gregorio Magno (Fig. 5) aparece efigiado como un anciano de barba y cabellos canosos y expresión bondadosa. Viste capa pluvial cerrada por un broche de pedrería cruciforme y cubre su cabeza con un camauro. La tiara papal de tres registros asoma levemente por el lado izquierdo depositada sobre una 

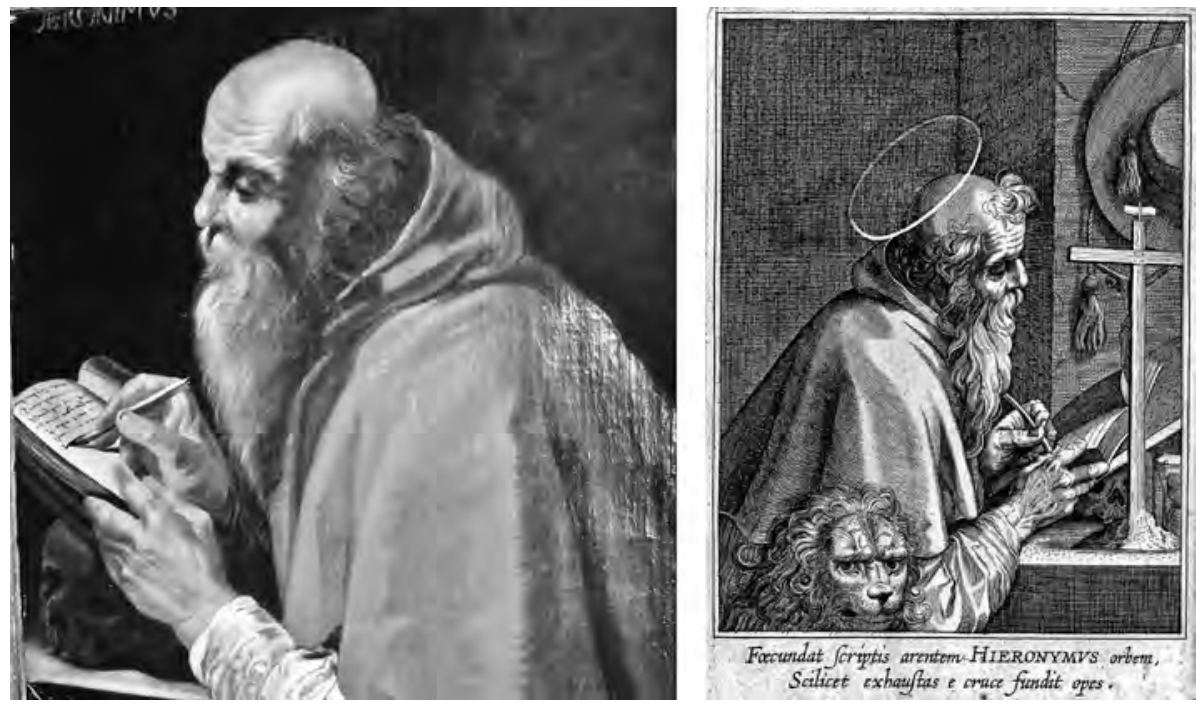

Figura 4. San Jerónimo. Mendiguren; A. Sadeler II. Grabado de San Jerónimo.

mesa. Otro atributo pontificio es la férula o cruz de tres travesaños florenzados y decrecientes, símbolo, como la tiara, de la triple autoridad de los papas. En el ángulo inferior izquierdo asoma un libro abierto que está leyendo San Gregorio. Se halla identificado por la inscripción: "S. GREGORIVS" y las únicas diferencias respecto al grabado son la eliminación de la tiara y el libro de canto que sirve de base al que lee el santo.

Nos hallamos ante cuatro lienzos barrocos de excelente factura que, si bien parten de composiciones manieristas, responden a un estilo naturalista y tenebrista. Las figuras de los Padres están iluminadas por focos de luz dirigidos que las hacen sobresalir de los fondos neutros, acercándolas así a los fieles. Partiendo de las estampas de A. Sadeler se ha resaltado el naturalismo en rostros, barbas e indumentarias. Los cuadros siguen tres esquemas compositivos, copiando los grabados de referencia, frontales los de San Agustín y San Gregorio Magno, de tres cuartos el de San Ambrosio y de riguroso perfil el de San Jerónimo. Los dos primeros aportan el elemento participativo, pues miran fijamente al espectador rompiendo su frontalidad con la disposición diagonal del báculo y la cruz pontifical, respectivamente. Aunque la paleta usada aquí se basa en la cuatricromía formada por los rojos, dorados, azules y blancos el resultado final es de unos cuadros coloristas que ahora se aprecia con más nitidez tras la restauración Ilevado a cabo en $2010^{24}$.

24. La restauración fue Ilevado a cabo por la empresa Croma Restauración y Conservación S. Coop. de Vitoria. 



Figura 5. San Gregorio Magno. Mendiguren; A. Sadeler II. Grabado de San Gregorio Magno.

Llaman la atención el intenso rojo de la capa pluvial de San Agustín y la esclavina cardenalicia de San Jerónimo y el dorado de las capas de San Gregorio Magno, salpicado de brocados, y San Ambrosio, con cenefa de perlas. El azul se reserva a prendas como los gorros que destacan las figuras de San Gregorio Magno y San Agustín.

\section{Las tablas del retablo de la Inmaculada de La Cerca}

A la iglesia románica de la Asunción de La Cerca, cercana a Medina de Pomar, se adosa la antigua capilla de los Hierro, presidida por un retablo de la Inmaculada Concepción del siglo XVII que alberga cuatro tablas de los Padres de la Iglesia. Esta capilla se abre en el lado del evangelio del presbiterio y, actualmente, ha sido convertida en sacristía. Las armas de esta familia, que se repiten en tres escudos de piedra, otro tallado en el retablo y la clave polar pintada, confirman el patronato de esta capilla. Sabemos que Gaspar (González) del Hierro fundó la capellanía a fines del XVI con cuatro misas semanales y una dotación de cien ducados de renta ${ }^{25}$. Este personaje fue alumno del colegio de San Bartolomé de Salamanca, provisor del obispado de Málaga y otorgó su últi-

25. VILLASANTE ORTEGA, A., La Junta de La Cerca y sus pueblos (I), Burgos, Juntas de La Cerca y Aldeas de Medina, 2005, p. 96. También estaba fundada en esta iglesia una obra pía con una renta de 150 ducados fundada por Agustín del Hierro. 
ma voluntad en Bilbao en 1597, abriéndose el testamento en la capital andaluza en $1600^{26}$. Se trata de una capilla funeraria clasicista, erigida probablemente a comienzos del siglo XVII, que adopta al exterior una planta poligonal irregular y se cierra mediante bóveda octogonal. Esta cubierta nos recuerda en última instancia a las bóvedas estrelladas de las capillas de enterramiento de los Velasco en la catedral de Burgos y la de la Concepción en el vecino monasterio de Santa Clara de Medina de Pomar.

Semioculto en el intradós del arco de ingreso a la capilla se localiza un escudo correiforme partido que sostiene un león con una argolla en la boca, motivo que ya aparecía en los sarcófagos romanos. En la diestra se dispone la banda de los Hierro y en la siniestra las trece estrellas de los Salazar. En el interior de la capilla encontramos otro escudo correiforme, también timbrado por una cabeza de león. En sus cuatro cuarteles aparecen la banda de los Hierro, un lobo pasante sobre una encina, grifo sobre tres gavillas de trigo doradas, y en el cuarto, cortado, cinco flores de lis y cinco estrellas. Al exterior y bajo la cornisa hallamos otro pequeño escudo cuartelado con la banda, las cinco estrellas, el lobo ante la encina y las cinco flores de lis. También la clave central se decora con un escudo repintado con la banda de los Hierro. En el escudo tallado del retablo se repite la disposición heráldica y las armas del escudete labrado en piedra del exterior de la capilla con la adición de la orladura con las trece estrellas de los Salazar. Finalmente, en el escudo de ángulo del antiguo palacio de los Hierro Salinas, que todavía se conserva en La Cerca, vemos estas mismas armas, diferenciándose únicamente en el yelmo con penacho y una orladura barroca.

Aunque no hemos encontrado en la bibliografía específica datos documentales directos sobre esta capilla, podemos apuntar que el posible fundador de la misma bien pudo ser el citado Gaspar (González) del Hierro y el primer patrono su hermano Agustín (González) del Hierro, residente en La Cerca y fallecido en los primeros años del siglo XVII ${ }^{27}$. Tuvo al menos tres hijos Ilamados Mateo, Agustín (+ 1660) y Juan Francisco (+ 1671) del Hierro Salinas Ilegando a ser los dos últimos destacados jueces en la España de Felipe IV. Ambos fueron alumnos en el Colegio de la Santa Cruz de Valladolid, doctores y catedráticos de derecho civil. Agustín del Hierro Salinas fue fiscal y oidor en la Chancillería de Granada y en el Consejo de Castilla y, asimismo, miembro del Consejo de Órdenes. Juan Francisco llegó a ser juez mayor de Vizcaya, Presidente de la Real Audiencia de Valladolid y oidor en La Coruña ${ }^{28}$. En relación con el fervor inma-

26. http://ortizdepinedo.com/f5494.htm. MARTÍ CEBALLOS, O., Historia genealógica de los Ceballos de La Rioja y sus entronques con otras familias en las tierras de Álava, Burgos y Vizcaya... T. II, Sevilla, Fabiola de Publicaciones Hispalenses, 2005, p. 582.

27. Ibídem. Fueron sus hermanos Casilda del Yerro y Gaspar del Yerro, colegial de San Bartolomé de Salamanca y provisor del obispado de Málaga que testó en Bilbao en 1597.

28. GARCÍA SÁINZ DE BARANDA, J., "El valle de Losa. Notas para su historia (continuación)", cap. XVIII, Hijos ilustres del valle de Losa, Boletín de la Comisión Provincial de Monu- 
culista de los Hierro, que dedicaron su capilla de patronato a la Concepción, conviene recordar que los dos hermanos se formaron y ocuparon cargos en Valladolid, ciudad en la que en 1618 el Ayuntamiento, la Universidad y la Chancillería, por impulso de la orden franciscana, hicieron voto en defensa de la Inmaculada Concepción ${ }^{29}$.

Todavía subsiste el palacio de los Hierro-Salinas que se alza sobre el solar de la que fue la torre de los Salazar y lugar de nacimiento de don Lope García de Salazar. Dado el empaque de este edificio fue modificado en 1955 y convertido en casa consistorial de La Cerca aunque hoy se halla abandonado. Se localiza al norte del caserío, exento y en la calle de la Fuente cerca de la iglesia. El palacio es obra clasicista de la primera mitad del siglo XVII de planta cuadrangular, aglomerado y con soportal de triple arquería de medio punto orientada al suroeste. Su fachada responde al esquema de tres por tres, es decir tres plantas y tres ejes de vanos, unificados por pilastras de orden gigante. Al sureste se abre, como resulta habitual en este tipo de palacios, lo que debió ser el mirador o solana. La fachada se prolonga con un ala estrecha que dota al conjunto de una planta en $L$, en una de cuyas esquinas se emplaza el escudo en ángulo barroco con las armas de los Hierro-Salinas. Medios torreones semicirculares, quizá reaprovechados de la antigua casa fuerte, sostienen este ala a modo de estribos.

Preside la capilla de la Inmaculada, patronato de los Hierro, un retablo clasicista (Fig. 6) de hacia 1625-1630 con banco, dos cuerpos, tres calles y ático con aletones curvilíneos y un fragmento de frontón curvo. Los soportes utilizados son columnas toscanas con el fuste entorchado sobre netos en el primer cuerpo y jónicas sobre el entablamento corrido en el segundo. El ático está centrado por las características pilastras ganchudas de tradición manierista. En sus extremos se situaban sendos escudos correiformes de la familia Hierro-Salazar, de los que solo ha llegado a nuestros días el del lado de la epístola. Cubre las superficies lisas una policromía decimonónica que imita tallos vegetales. Se trata de un retablo mixto de pintura y escultura que propone un programa iconográfico contrarreformista de defensa de la Inmaculada Concepción, en el que adquieren un protagonismo los cuatro Doctores de la Iglesia Latina. A diferencia de lo que hemos visto en Mendiguren, este retablo burgalés ha conservado sin cambios notables la disposición original de su programa pese a presentar gran deterioro y mutilaciones. Se han perdido el fragmento de frontón y el escudo con las armas de los patronos del lado del evangelio, el frontón y el panel del fondo del ático y gran parte de la tabla de San Ambrosio.

mentos y de la Institución Fernán González, 114 (1951), p. 437. VILLASANTE ORTEGA, A., ob. cit., pp. 92-93 y 96.

29. ANDRÉS ORDAX, S., "Ante el sesquicentenario de la Inmaculada: el misterio, desde la devoción y la iconografía hasta la Academia de la Purísima Concepción", Boletín de la Real Academia de Bellas Artes de la Purísima Concepción, 40 (2005), pp. 9-36. 


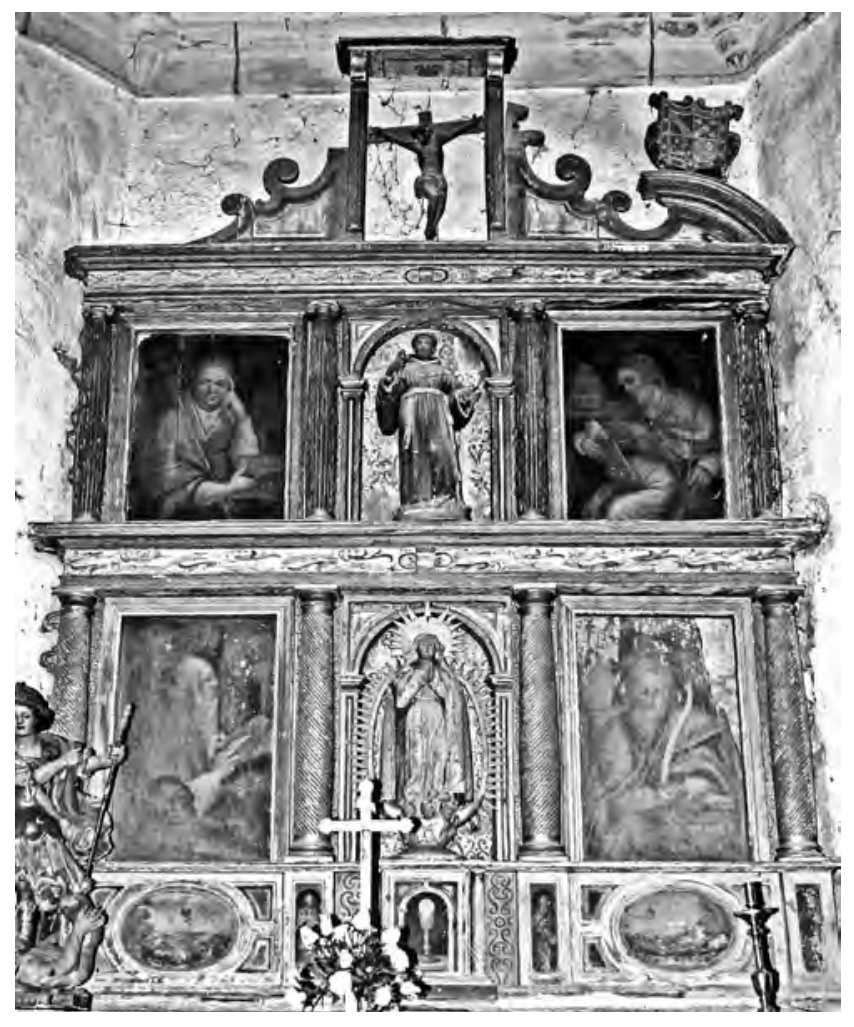

Figura 6. Retablo de la Inmaculada Concepción. Sacristía (antigua capilla de los Hierro). Parroquia de la Asunción. La Cerca (Burgos).

Los netos del banco sirven de marco a pinturas de los cuatro evangelistas erguidos, Lucas, Marcos, Mateo y Juan que centran los óvalos con paisajes de comienzos del siglo XIX. En la portezuela del sagrario vemos la pintura de un cáliz barroco con la Forma. En la calle central se suceden las tallas, coetáneas al retablo, de la Inmaculada, que sigue el modelo popularizado por Gregorio Fernández, San Francisco de Asís y un pequeño Cristo crucificado en el ático. La presencia aquí del fundador de los frailes menores queda justificada por el carácter funerario de la capilla y por la cercanía del convento de San Francisco de Medina de Pomar, hoy desaparecido. Responde a la iconografía barroca de San Francisco orante ante la cruz con los brazos abiertos ${ }^{30}$. En las calles laterales se emplazan las tablas de los cuatro Doctores como defensores de la virginidad de María, saliendo así de sus ubicaciones canónicas en netos y bancos y adqui-

30. VÉLEZ CHAURRI, J. J. y ECHEVERRÍA GOÑI, P. L., Representaciones postridentinas de San Francisco de Asís en la diócesis de Vitoria, Bilbao, Etor, 1991, p. 50. Con esta iconografía realista se culmina así un proceso de simplificación de la Estigmatización. 
Figura 7. San Agustín. La Cerca.

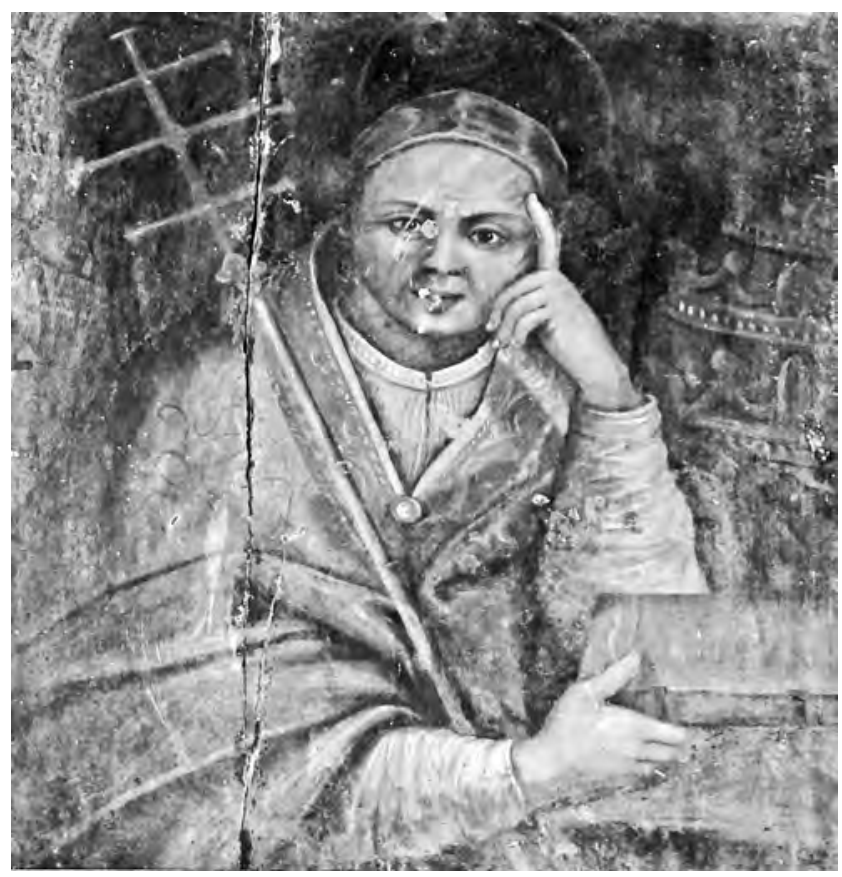

riendo mayor tamaño y relevancia. Una lectura racional de su disposición nos muestra a San Jerónimo, San Ambrosio, San Agustín y San Gregorio Magno, pese a que este último lleva la inscripción errónea de San Ambrosio. Nos encontramos ante cuatro pinturas barrocas tenebristas, coetáneas al retablo, que copian literalmente los grabados de la serie de los Doctores de Johann Friedrich Greuter, si bien la baja calidad de su ejecución desmerece de su modelo gráfico. Se utiliza en ellas una paleta restringida a base de tres colores entre los que destaca el vivo rojo de la esclavina y el capelo de San Jerónimo y los camauros de San Agustín y San Gregorio. Las capas pluviales doradas de tres de los Doctores se adornan con cenefas recorridas por roleos en rojo y enveses de color verde. Sirven de fondo a estas lujosas prendas las albas blancas ceñidas por cíngulos.

La tabla de San Jerónimo de La Cerca sigue la iconografía del grabado de Greuter que lo representa como anciano y erudito traductor de la Biblia. Ha simplificado la composición al eliminar el crucifijo de mesa, el reloj de arena, la calavera y el nimbo. El único elemento que recuerda su condición de eremita penitente es el león del desierto que, dispuesto en primer plano, actúa de elemento participativo. La pintura de San Agustín (Fig. 7) sigue en su inconfundible esquema compositivo e indumentaria los del grabado homónimo de Greuter, al que ha añadido aquí la férula de triple travesaño y la tiara papal que procede del grabado de San Gregorio Magno de la misma serie. Este atentado al decoro 

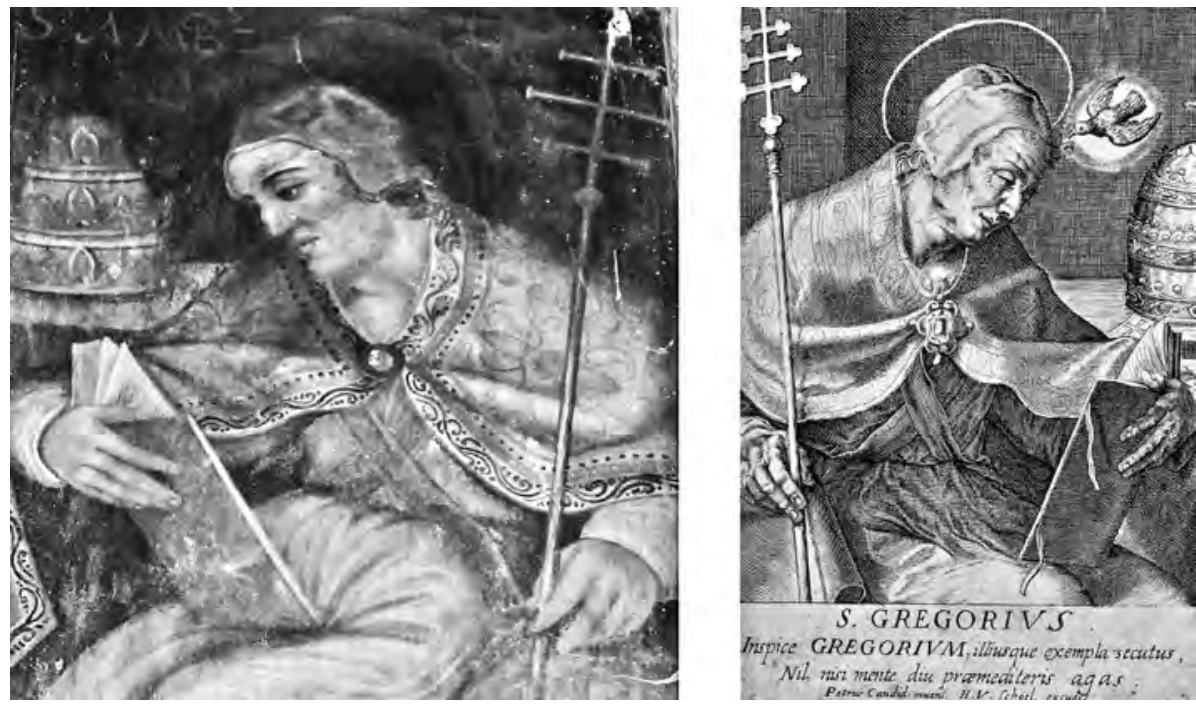

Figura 8. San Gregorio Magno. La Cerca; Johan Friedrich Greuter. Grabado de San Gregorio Magno.

da como resultado en el retablo de La Cerca la presencia de dos Padres con atributos pontificios, San Gregorio Magno que los Ileva en propiedad y San Agustín que no obtuvo tal dignidad. El detalle que caracteriza a San Agustín como eminente pensador, teólogo y padre de la filosofía, es el gesto de apoyar el rostro en la mano con el índice sobre la sien. Como en la tabla de la serie de Mendiguren se ha suprimido al niño de la Visión y, como se ha señalado, su mitra ha sido sustituida impropiamente por la tiara papal.

La tabla de San Gregorio Magno (Fig. 8) sigue fielmente el grabado que Greuter realizó sobre el papa con la tiara y el báculo triple pontificio a pesar de que, fruto de una confusión, está identificado en la parte superior como "S. $\mathrm{AMB}(\mathrm{RO}) \mathrm{S}(\mathrm{IO})^{\prime \prime}$. Esta confusión es debida a que Greuter utilizó para esta composición el mismo tipo y esquema del San Ambrosio grabado por Sadeler, sustituyendo los atributos. Respecto al grabado original de San Gregorio, en el cuadro de La Cerca únicamente se omite la paloma del Espíritu Santo en un resplandor. La tabla más deteriorada del conjunto es la que representa a San Ambrosio obispo de Milán como lo acredita la mitra dispuesta sobre la mesa, los libros depositados en el escritorio y, especialmente el látigo con el que fustigó a los arrianos. Copia en su disposición fielmente el grabado de San Ambrosio de Greuter. El tipo físico de anciano y la actitud coincide con el grabado de San Gregorio Magno de la serie de Sadeler. Como hemos visto la inferior calidad de estas pinturas respecto a las de Mendiguren, se compensa con su integración en el programa contrarreformista original del siglo XVII. 